\title{
Microscopic Patterns of the Colonic Mucosal Surface. Investigations in Human Subjects and Experi- mental Animals
}

In this paper the results are reported of 2 investigations performed using the technique for microscopical study of the surface of the large bowel ${ }^{1}$.

The first investigation concerns further research into the appearance of the colonic surface in normal subjects; the second one, performed with experimental animals, describes the variations of the morphology of the large bowel surface induced by local changes of temperature.

Investigations regarding humans were made with 36 biopsies of large bowel (Table) performed either by endto-end intubation ${ }^{2,3}$ or by sigmoidoscopy, in 26 subjects in whom the normality of the intestinal tract had been previously determined by clinical examinations, sigmoidoscopy and double contrast enema.

No. and site of the biopsies

$\begin{array}{llrl}3 & \text { ascending colon } & 3 & \text { descending colon } \\ 1 & \text { transverse colon } & 29 & \text { sigmoid }\end{array}$

As experimental animals, 6 adult male albino rats weighing about $130 \mathrm{~g}$, divided into 3 groups of 2 animals each, were used. All rats were anaesthetized by i.p. injection of a $0.2 \%$ solution of $N$ ethyl-urethan-chloralose $(1 \mathrm{ml} / \mathrm{kg}$ body weight). After laparatomy the caecum in situ was opened longitudinally and slightly distended by pins. In the animals of the first group, saline solution at $37^{\circ} \mathrm{C}$ was continuously dropped onto the mucosal surface of the caecum.

In the 2 other groups, saline solution at 4 and $40^{\circ} \mathrm{C}$ was used. After $10 \mathrm{~min}$ of treatment with saline solution, serial photographs of the surface of the caecum were taken in each animal with a Leitz Orthomat apparatus.

Results. We have confirmed that, in human subjects, the colonic mucosa may assume 2 surface pictures: the flat and the papillary one. The first was noted in 26 and the latter in 9 specimens. In 1 case the openings of the crypts were visible at the bottom of cylindrical pits on the mucosal surface.
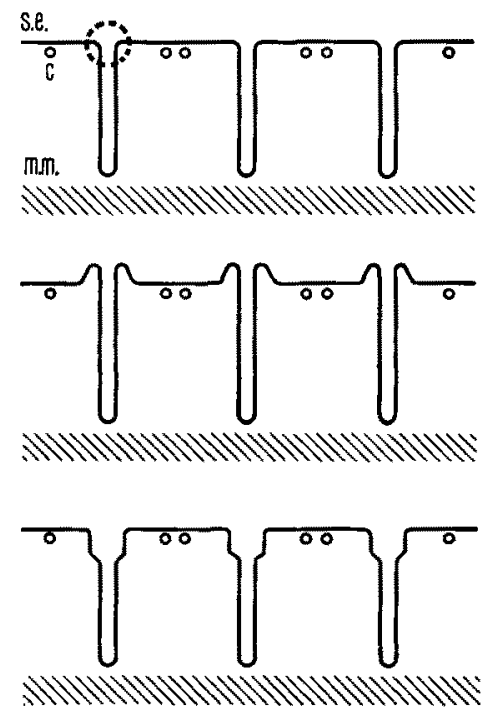

Schematic representation of the different surface patterns as a consequence of the automodelling activity of the mucosal area (encircled by a broken line). s.e., superficial epithelium; $c$, capillaries; m.m., muscularis mucosae.
In some instances, the network of the superficial capillaries on the mucosal surface describe polygonal areas which contain the openings of the crypts. At times, each side of a polygonal area is limited by 2 parallel longitudinal capillaries. No differences were found between the specimens from the various regions of the large bowel.

In living rats the mucosal surface of the caecum, maintained at $37^{\circ} \mathrm{C}$, shows the same 2 main aspects as the human colon. When the mucosa of the caecum is maintained at $4^{\circ} \mathrm{C}$, the superficial capillaries are not visible and the mucosa is pale. The openings of the crypts, set at the bottom of small depressions of the mucosal surface, are cleft-shaped.

When the caecum surface is maintained at $40^{\circ} \mathrm{C}$, the superficial capillaries are clearly evident. The papillary pattern is manifest and the openings of the crypts are large and round. Sometimes large vessels surround a few openings of the crypts and then branch into capillaries enclosing polygonal areas similar to those observed in normal human colonic mucosa.

Discussion. We think that the different pictures observed are the end-result of the automodelling activity of the muscularis mucosae, and, in fact, this structure displayed autonomous mechanical activity in pharmacological studies performed on isolated colonic mucosa in vitro".

We suggest that each opening of the crypts is surrounded by 2 concentric areas. The outer one, represented by the most peripheral part of the polygonal surface, seems stable, whereas the inner one, surrounding the opening of the crypts, seems movable since it can be seen at varying levels (equal, higher or lower; see Figure) in relation to the peripheral surface.

The different positions of the inner area could, in this way, determine the various morphological patterns of the mucosal surface. Moreover, the subepithelial capillary network also plays an important role in establishing the superficial mucosal pattern.

We suggest that the inner area may condition the diameter of the openings of the crypts and eventually the amount of mucus discharged into the intestinal lumen. In fact, in both humans and experimental animals, the openings vary from round to cleft-like shapes ${ }^{1,5}$.

Riassunto. La mucosa del grosso intestino dell'uomo e degli animali, presenta vari aspetti sostenuti verosimilmente da differenti atteggiamenti funzionali della muscolaris mucosae. Lo studio è stato condotto su frammenti di mucosa di colon umano prelevati mediante biopsia e sperimentalmente su ceco di ratti.

L. ONORI, V. Greco,

A. FABbrini and A. Torsoli

II Clinica Medica and Istituto di Semeiotica Medica dell'Università, 00100 Roma (Italy), 22 April 1968.

1 A. Fabbrint, A. Torsoli, A. Alessandrint, L. Onori, V. Greco, C. CASAle and P. Arullani, Experientia 22, 408 (1966).

2 C. Colagrande, P. Arullani and C. Casale, Am. J. dig. Dis. 11, 389 (1966).

3 A. Torsoli, P. Arullani and C. Casale, Gut 8, 192 (1967).

4 L. Onori, A. Crema, C. A. Friedmann and A. Torsolt, in press.

s Aided by grants from Consiglio Nazionale delle Ricerche. 